\section{JURNAL EKONOMI EFEKTIF}

ISSN : $2622-8882$, E-ISSN : 2622-9935

Jurnal Ekonomi Efektif, Vol. 4, No. 2, Januari 2022 @ Prodi Manajemen Fakultas Ekonomi

Universitas Pamulang

\title{
PENGARUH PERENCANAAN KARIER TERHADAP KINERJA PEGAWAI PADA KANTOR BADAN PERTANAHAN NASIONAL KOTA BEKASI
}

\author{
Mutia Tri Yuliyati ${ }^{1}$, Sarwani ${ }^{*}$ \\ Universitas Pamulang, Tangerang Selatan, Banten, Indonesia \\ $\underline{\text { mutiayuliyati@gmail.com }}{ }^{1}, \underline{\text { dosen} 00005 @ \text { unpam.ac.id }^{2 *}}$
}

\begin{abstract}
Manuskrip: November -2021; Ditinjau: Desember-2021; Diterima: Desember-2021; Online: Januari -2022;
\end{abstract} Diterbitkan: Januari-2022

\begin{abstract}
ABSTRAK
Penelitian ini bertujuan untuk mengetahui pengaruh perencanaan karier terhadap kinerja pegawai pada Kantor Badan Pertanahan Nasional Kota Bekasi. Metode yang digunakan adalah explanatory research dengan sampel sebanyak 87 responden. Teknik analisis menggunakan analisis statistik dengan pengujian regresi, korelasi, determinasi dan uji hipotesis. Hasil penelitian ini variabel perencanaan karier diperoleh nilai rata-rata skor sebesar 3,395 dengan kriteria baik. Variabel kinerja pegawai diperoleh nilai rata-rata skor sebesar 3,816 dengan kriteria baik. Perencanaan karier berpengaruh positif dan signifikan terhadap kinerja pegawai dengan nilai persamaan regresi $\mathrm{Y}=12,211+0,764 \mathrm{X}$, dan nilai koefisien korelasi 0,727 atau memiliki tingkat hubungan yang kuat dengan nilai determinasi 52,8\%. Uji hipotesis diperoleh signifikansi $0,000<0,05$.
\end{abstract}

\section{Kata Kunci: Perencanaan Karier, Kinerja Pegawai}

\section{ABSTRACT}

This study aims to determine the effect of career planning on employee performance at the Bekasi City National Land Agency Office. The method used is explanatory research with a sample of 87 respondents. The analysis technique uses statistical analysis with regression, correlation, determination and hypothesis testing. The results of this study of career planning variables obtained an average score of 3.395 with good criteria. Employee performance variable obtained an average score of 3.816 with good criteria. Career planning has a positive and significant effect on employee performance with a regression equation value of $Y=12.211$ $+0.764 X$, and a correlation coefficient value of 0.727 or has a strong relationship with a determination value of 52.8\%. Hypothesis testing obtained a significance of $0.000<0.05$.

Keywords: Career Planning, Employee Performance 


\section{PENDAHULUAN}

\section{A. Latar Belakang}

Perencanaan karier merupakan hal yang sangat penting bagi sumber daya manusia dalam setiap organisasi terutama organisasi yang memberikan pelayanan kepada masyarakat khususnya perpustakaan. Perencanaan karier pada suatu organisasi bisa saja menentukan motivasi kerja dari sumber daya manusia. Motivasi kerja sendiri dapat dipengaruhi oleh perencenaan karier dimana sumber daya manusia mendapatkan motivasi dari perencanaan karier untuk kedepannya, tentu saja sumber daya manusia melihat perencanaan karier pada suatu organisasi dimana sumber daya manusia itu bekerja hal ini juga terkait dengan kinerja sumber daya manusia yang diberikan kepada organisasi. Sumber daya manusia tentu diharapkan memberikan kinerja yang maksimal demi menunjang tercapainya tujuan dari organisasi. Meskipun begitu kinerja yang maksimal juga tidak bisa terlepas juga dari adanya motivasi kerja yang dimiliki oleh sumber daya manusia tersebut.

Kinerja yang maksimal dari sumber daya manusia merupakan sebuah hasil yang di dapat oleh sumber daya manusia itu sendiri karena sumber daya manusia puas akan prestasi kerjanya, kepuasan dalam kerja karyawan diharapkan mampu membuat karyawan memberikan kinerja terbaiknya untuk melayani masyarakat, pada dasarnya kinerja tentu saja dituntut oleh instansi atau perusahaan terutama perpustakaan yang langsung melayani masyarakat. Kinerja yang dimiliki karyawan dituntut untuk terus meningkat. Kinerja yang selalu maksimal dan terus meningkat memerlukan evaluasi kinerja karyawan dan melakukan serangkaian perbaikan agar selalu meningkatkan kualitas kinerja karyawan sehingga instansi atau perusahaan dapat berkembang dan unggul, atau minimal tetap dapat bertahan. Output yang maksimal dari sumber daya manusia tentu meberikan dampak positif terhadap organisasi khususnya perpustakaan. Namun kinerja yang tidak maksimal juga merugikan bagi perpustakaan terlebih perpustakaan adalah organisasi non-profit dimana perpustakaan tentu tidak semata-mata mencari keuntungan finansial melainkan ditujukan kepada pelayanan umum atau kepentingan sosial.

Kinerja yang maksimal sendiri memiliki makna terjadinya peningkatan efisiensi kerja, efektivitas kerja, atau kualitas yang tinggi dari penyelesaian serangkaian tugas yang dibebankan kepada seorang karyawan dalam suatu organisasi atau perusahaan. Kinerja sendiri tentu dipengaruhi oleh beberapa faktor, salah satunya menurut Keith Davis (dalam Mangkunegara 20157) kinerja dipengaruhi oleh faktor Motivation atau faktor motivasi. Perpustakaan sebagai penyedia informasi diharapkan memiliki sumber daya manusia yang berkinerja tinggi sehingga mampu melayani pengunjung dengan maksimal dan juga memberikan kesan positif terhadap perpustakaan itu sendiri. Kemampuan pekerja sendiri dalam bidangnya juga mempengaruhi bagaimana kinerja pekerja tersebut, selain itu motivasi juga harus terus diberikan agar pekerja memberikan kinerja maksimal.

Banyak strategi yang dapat dilakukan oleh organisasi khususnya perpustakaan dalam meningkatkan kinerja pegawai perpustakaan itu. Diantaranya memberikan persamaan kesempatan karier dimana pegawai perpustakaan menginginkan persamaan dalam sistem kenaikan pangkat atau promosi dalam hal kemajuan karier selain itu pegawai juga menginginkan berperan aktif dalam pengembangan perencanaan karier dari pegawai itu sendiri dengan memberikan kinerja yang maksimal sebagai nilai yang bisa dilihat oleh pimpinan, Selain itu faktor motivasi kerja kepada pegawai juga bisa diharapkan memberikan stimulus bagi pegawai untuk memberikan kinerja yang maksimal, selain itu dengan memberikan motivasi kepada pegawai 
perpustakaan diharapkan bisa lebih percaya diri dalam bekerja, pemberian motivasi sendiri menurut Herzberg (dalam Siagian 2004:165) berpendapat bahwa apabila para manajer dalam hal ini kepala perpustakaan ingin memberi motivasi kepada para bawahannya, yang perlu ditekankan adalah faktor-faktor yang menimbulkan rasa puas, yaitu dengan mengutamakan faktor motivasi yang sifatnya intrinsic. Peningkatan kinerja pada perpustakaan tentu sangat diperlukan untuk bagaimana perpustakaan tersebut membuat citra baik, namun tidak semua pegawai pada sebuah perpustakaan mempunyai kinerja yang maksimal, tentu dalam sebuah perpustakaan khususnya perpustakaan umum memiliki pegawai perpustakaan yang berasal dari berbagai macam bidang mulai dari teknisi perpustakaan yang berasal dari berbagai bidang sampai pustakawan yang memang ahli pada bidang perpustakaan dengan latar belakang yang berbeda bisa saja pegawai perpustakaan memiliki kinerja yang berbeda-beda pula. Namun perpustakaan sendiri berharap bahwa kinerja pada pegawainya maksimal, motivasi disini diharapkan bisa membantu membuat kinerja pegawai perpustakaan semakin maksimal.

Salah satu unsur penting dalam sumber daya manusia adalah perencanaan karier, jika pegawai ingin meningkatkan kariernya maka pegawai diharapkan mampu mengevaluasi diri dimana dimaksudkan pegawai mampu mengidentifikasi apa saja sebagai kekurangannya sehingga segera diperbaiki dan juga apa saja keunggulannya sehingga mampu ditingkatkan lagi, hal ini akan menjadi value tersendiri bagi pegawai jika dilihat dari sudut pandang pimpinan, selain itu pegawai diharapkan mampu mengelola diri dan bukan pasrah pada keadaan yang ada. Diharapkan agar usaha-usaha dalam meningkatkan karier tidak sia-sia maka diperlukan perencanaan karier. Perencanaan karier pun diharapkan mampu meningkatkan motivasi kerja pegawai dilain sisi juga diharapkan mampu meningkatkan kinerja pegawai.

Berdasarkan uraian di atas, maka penulias tertarik untuk melakukan penelitian dengan judul "Pengaruh Perencanaan Karier Terhadap Kinerja Pegawai Pada Kantor Badan Pertanahan Nasional Kota Bekasi".

\section{B. Rumusan Masalah}

1. Bagaimana perencanaan karier pada Kantor Badan Pertanahan Nasional Kota Bekasi?

2. Bagaimana kinerja pegawai pada Kantor Badan Pertanahan Nasional Kota Bekasi ?.

3. Adakah pengaruh antara perencanaan karier terhadap kinerja pegawai pada Kantor Badan Pertanahan Nasional Kota Bekasi ?.

\section{Tujuan Penelitian}

1. Untuk mengetahui kondisi perencanaan karier pada Kantor Badan Pertanahan Nasional Kota Bekasi.

2. Untuk mengetahui kondisi kinerja pegawai pada Kantor Badan Pertanahan Nasional Kota Bekasi.

3. Untuk mengetahui pengaruh perencanaan karier terhadap kinerja pegawai pada Kantor Badan Pertanahan Nasional Kota Bekasi.

\section{TINJAUAN PUSTAKA}

\section{Perencanaan Karier}

Menurut Minto (2020:24) perencanaan karir adalah proses melalui masa seseorang memilih sasaran karir (posisi di waktu yang akan datang) dan jalur karirnya (pola pekerjaan yang berurutan yang membentuk karir). 


\section{Kinerja Pegawai}

Menurut Mangkunegara (2019:75) pengertian kinerja adalah hasil kerja secara kualitas dan kuantitas yang dicapai oleh seorang pegawai dalam melaksanakan tugasnya sesuai dengan tanggung jawab yang diberikan kepadanya.

\section{METODE PENELITIAN}

\section{Populasi}

Yang dijadikan sebagai populasi dalam penelitian ini adalah responden yang berjumlah 87 responden Kantor Badan Pertanahan Nasional Kota Bekasi

\section{Sampel}

Teknik pengambilan sampling dalam penelitian ini adalah sampel jenuh, dimana semua anggota populasi dijadikan sebagai sampel. Dengan demikian sampel dalam penelitian ini sampel yang digunakan berjumlah 87 responden.

\section{Jenis Penelitian}

Jenis penelitian yang dipakai adalah asosiatif, dimana tujuannya adalah untuk mengetahui atau mencari keterhubungan antara variabel independen terhadap variabel dependennya

\section{Metode Analisis Data}

Dalam menganalisis data digunakan uji validitas, uji reliabilitas, analisis regresi linier sederhana, analisis koefisien korelasi, analisis koefisien determinasi dan pengujian hipotesis.

\section{HASIL PENELITIAN}

\section{Analisis Deskriptif}

Pada pengujian ini digunakan untuk mengetahui skor minimum dan maksimum skor tertinggi, ratting score dan standar deviasi dari masing-masing variabel. Adapun hasilnya sebagai berikut:

Tabel 1. Hasil Analisis Descriptive Statistics

\section{Descriptive Statistics}

\begin{tabular}{|l|r|r|r|r|r} 
& N & \multicolumn{1}{c|}{ Minimum } & Maximum & Mean & \multicolumn{1}{c}{ Std. Deviation } \\
\hline Perencanaan karier (X) & 87 & 29 & 44 & 33.95 & 3.912 \\
\hline Kinerja Pegawai (Y) & 87 & 29 & 49 & 38.16 & 4.114 \\
\hline Valid N (listwise) & 87 & & & & \\
\hline
\end{tabular}

Perencanaan karier diperoleh varians minimum sebesar 29 dan varians maximum 44 dengan ratting score sebesar 3,395 dengan standar deviasi 3,912. Skor ini termasuk pada rentang sakala 3,40 - 4,19 dengan kriteria baik atau setuju. Kinerja pegawai diperoleh varians minimum sebesar 29 dan varians maximum 49 dengan ratting score sebesar 3,816 dengan standar deviasi 4,114. Skor ini termasuk pada rentang sakala 3,40 $-4,19$ dengan kriteria baik atau setuju.

\section{Analisis Kuantitatif}

Pada analisis ini dimaksudkan untuk mengetahui pengaruh variabel independen terhadap variabel dependen. Adapun hasil pengujian sebagai berikut:

\section{a. Analisis Regresi Linier Sederhana}

Uji regresi ini dimaksudkan untuk mengetahui perubahan variabel dependen jika variabel independen mengalami perubahan. Adapun hasil pengujiannya sebagai berikut: 
Tabel 2. Hasil Pengujian Regresi Linier Sederhana

\begin{tabular}{|c|c|c|c|c|c|}
\hline \multirow[b]{3}{*}{ Model } & \multicolumn{3}{|c|}{ Coefficients ${ }^{\mathrm{a}}$} & \multirow[b]{3}{*}{$\mathrm{t}$} & \multirow[b]{3}{*}{ Sig. } \\
\hline & \multicolumn{2}{|c|}{$\begin{array}{l}\text { Unstandardized } \\
\text { Coefficients }\end{array}$} & \multirow{2}{*}{$\begin{array}{c}\text { Standardized } \\
\text { Coefficients } \\
\text { Beta }\end{array}$} & & \\
\hline & B & Std. Error & & & \\
\hline $1 \quad$ (Constant) & 12.211 & 2.679 & & 4.558 & .000 \\
\hline Perencanaan karier $(\mathrm{X})$ & .764 & .078 & .727 & 9.751 & .000 \\
\hline
\end{tabular}

a. Dependent Variable: Kinerja Pegawai (Y)

Berdasarkan hasil pengujian pada tabel di atas, diperoleh persamaan regresi $\mathrm{Y}$ $=12,211+0,764 X$. Dari persamaan tersebut dijelaskan sebagai berikut:

1) Konstanta sebesar 12,211 diartikan jika perencanaan karier tidak ada, maka telah terdapat nilai kinerja pegawai sebesar 12,211 point.

2) Koefisien regresi perencanaan karier sebesar 0,764 , angka ini positif artinya setiap ada peningkatan perencanaan karier sebesar 0,764 point maka kinerja pegawai juga akan mengalami peningkatan sebesar 0,764 point.

\section{b. Analisis Koefisien Korelasi}

Analisis koefisien korelasi dimaksudkan untuk mengetahui tingkat kekuatan hubungan dari variabel independen terhadap variabel dependen. Adapun hasil pengujian sebagai berikut:

Tabel 3. Hasil Pengujian Koefisien Korelasi Perencanaan karier Terhadap Kinerja

Pegawai.

\begin{tabular}{|c|c|c|c|}
\hline \multicolumn{4}{|c|}{ Correlations $^{\mathbf{b}}$} \\
\hline & & $\begin{array}{c}\text { Perencanaan } \\
\text { karier }(X)\end{array}$ & $\begin{array}{c}\text { Kinerja } \\
\text { Pegawai (Y) }\end{array}$ \\
\hline \multirow{2}{*}{ Perencanaan karier (X) } & Pearson Correlation & 1 & $.727^{* *}$ \\
\hline & Sig. (2-tailed) & & .000 \\
\hline \multirow[t]{2}{*}{ Kinerja Pegawai (Y) } & Pearson Correlation & $.727^{* *}$ & 1 \\
\hline & Sig. (2-tailed) & .000 & \\
\hline
\end{tabular}

Berdasarkan hasil pengujian diperoleh nilai korelasi sebesar 0,727 artinya perencanaan karier memiliki hubungan yang kuat terhadap kinerja pegawai.

\section{c. Analisis Koefisien Determinasi}

Analisis koefisien determinasi dimaksudkan untuk mengetahui besarnya persentase pengaruh dari variabel independen terhadap variabel dependen. Adapun hasil pengujian sebagai berikut:

Tabel 4. Hasil Pengujian Koefisien Determinasi Perencanaan karier Terhadap

Kinerja Pegawai.

Model Summary

\begin{tabular}{ll|c|c|c} 
Model & R & R Square & $\begin{array}{c}\text { Adjusted R } \\
\text { Square }\end{array}$ & $\begin{array}{l}\text { Std. Error of } \\
\text { the Estimate }\end{array}$ \\
\hline 1 & $.727^{\mathrm{a}}$ & .528 & .522 & 2.843 \\
\hline \multicolumn{2}{l}{ a. Predictors: (Constant), Perencanaan karier (X) }
\end{tabular}

Berdasarkan hasil pengujian diperoleh nilai determinasi sebesar 0,528 artinya perencanaan karier memiliki kontribusi pengaruh sebesar 52,8\% terhadap kinerja pegawai, sedangkan sisanya sebesar 47,2\% dipengaruhi oleh faktor lain yang tidak dilakukan penelitian. 


\section{d. Uji Hipotesis}

Pengujian hipotesis dengan uji t digunakan untuk mengetahui hipotesis mana yang diterima. Rumusan hipotesis: Terdapat pengaruh yang signifikan perencanaan karier terhadap kinerja pegawai.

Tabel 5. Hasil Uji Hipotesis Perencanaan karier Terhadap Kinerja Pegawai.

\begin{tabular}{|c|c|c|c|c|c|}
\hline \multirow[b]{3}{*}{ Model } & \multicolumn{3}{|c|}{ Coefficients $^{\mathrm{a}}$} & \multirow[b]{3}{*}{$\mathrm{t}$} & \multirow[b]{3}{*}{ Sig. } \\
\hline & \multicolumn{2}{|c|}{$\begin{array}{l}\text { Unstandardized } \\
\text { Coefficients }\end{array}$} & \multirow{2}{*}{$\begin{array}{c}\text { Standardized } \\
\text { Coefficients } \\
\text { Beta }\end{array}$} & & \\
\hline & B & Std. Error & & & \\
\hline 1 (Constant) & 12.211 & 2.679 & & 4.558 & .000 \\
\hline Perencanaan karier $(\mathrm{X})$ & .764 & .078 & .727 & 9.751 & .000 \\
\hline
\end{tabular}

a. Dependent Variable: Kinerja Pegawai (Y)

Berdasarkan hasil pengujian pada tabel di atas, diperoleh nilai thitung $>\mathrm{t}$ tabel atau $(9,751>1,988)$, dengan demikian hipotesis yang diajukan bahwa terdapat pengaruh yang signifikan atara perencanaan karier terhadap kinerja pegawai diterima.

\section{Pembahasan Hasil Penelitian}

\section{Kondisi Jawaban Responden Variabel Perencanaan karier}

Berdasarkan jawaban responden, variabel perencanaan karier diperoleh ratting score sebesar 3,395 berada di rentang skala 3,40 - 4,19 dengan kriteria baik atau setuju.

\section{Kondisi Jawaban Responden Variabel Kinerja Pegawai}

Berdasarkan jawaban responden, variabel kinerja pegawai diperoleh ratting score sebesar 3,816 berada di rentang skala 3,40 - 4,19 dengan kriteria baik atau setuju.

\section{Pengaruh Perencanaan karier Terhadap Kinerja Pegawai}

Perencanaan karier berpengaruh signifikan terhadap kinerja pegawai dengan persamaan regresi $\mathrm{Y}=12,211+0,764 \mathrm{X}$, nilai korelasi sebesar 0,727 atau memiliki hubungan yang kuat dengan kontribusi pengaruh sebesar 52,8\%. Pengujian hipotesis diperoleh nilai $\mathrm{t}$ hitung $>\mathrm{t}$ tabel atau $(9,751>1,988)$. Dengan demikian hipotesis yang diajukan bahwa terdapat berpengaruh signifikan antara perencanaan karier terhadap kinerja pegawai diterima.

\section{KESIMPULAN DAN SARAN}

\section{Kesimpulan}

a. Variabel perencanaan karier diperoleh ratting score sebesar 3,395 berada di rentang skala 3,40-4,19 dengan kriteria baik atau setuju.

b. Variabel kinerja pegawai diperoleh ratting score sebesar 3,816 berada di rentang skala 3,40 - 4,19 dengan kriteria baik atau setuju.

c. Perencanaan karier berpengaruh signifikan terhadap kinerja pegawai dengan persamaan regresi $\mathrm{Y}=12,211+0,764 \mathrm{X}$, nilai korelasi sebesar 0,727 atau kuat dan kontribusi pengaruh sebesar 52,8\% sedangkan sisanya sebesar 47,2\% dipengaruhi faktor lain. Uji hipotesis diperoleh nilai t hitung $>\mathrm{t}$ tabel atau $(9,751>1,988)$.

\section{Saran}

a. Salah satunya cara terkait dengan perencanaan karir. Perencanaan itu mesti ada sebelum kita melakukan kegiatan apapun, tentu saja agar kegiatan tersebut berjalan 
dengan lancaer dengan menerapkan proses dengan penuh pertimbangan saat seseorang jadi memiliki pemahaman mengenai ketrampilan, pengetahuan, motivasi, dan karakteristik pribadi lainnya dan memantapkan rencana tindak untuk mencapai tujuan spesifik.

b. Kinerja organisasi dapat ditingkatkan dengan memberdayakan pegawai dengan menegakkan peraturan yang baik dan pemberian motivasi yang lebih inten lagi.

\section{DAFTAR PUSTAKA}

Abdullah. M (2014). Manajemen dan Evaluasi Kinerja Pegawai. Yogyakarta: Penerbit Aswaja Pressindo.

Algifari. (2015). Analisis Regresi untuk Bisnis dan Ekonomi. Yogyakarta: BPFE.

Arikunto, Suharsimi (2014). Prosedur Penelitian Suatu Pendekatan Praktek. Jakarta: Rineka Cipta.

Bangun, Wilson. (2012). Manajemen Sumber Daya Manusia. Jakarta: Erlangga

Bejo Siswanto (2013) Manajemen Tenaga Kerja Rancangan dalam Pendayagunaan dan Pengembangan Unsur Tenaga Kerja. Bandung: Sinar Baru.

Dessler, G. (2006.). Manajemen Sumber Daya Manusia. Jilid II. Jakarta: Indeks.

Edi Sutrisno (2016). Manajemen Sumber Daya Manusia. Jakarta: Prenadamedia Group.

George Terry R \& Rue, Leslie W. Rue (2016). Dasar-Dasar Manajemen. Jakarta Bumi Aksara.

Gerry Dessler (2016). Human Resources Management. Prenticehall. London: International Inc.

Handoko (2016). Manajemen Personalia dan Sumberdaya Manusia. Yogyakarta: BPFE.

Hasibuan, Malayu S.P. (2016). Manajemen Sumber Daya Manusia. Edisi Revisi. Jakarta: PT Bumi Aksara.

Imam Ghozali (2017). “Aplikasi Analisis Multivariate Dengan Program SPSS”. Edisi Kelima. Semarang: Badan Penerbit Undip.

Istijanto (2014) "Riset Sumber Daya Manusia". Jakarta: PT. Gramedia Pustaka

Kharis, Ismu Fadli (2011). Studi Mengenai Impulse Buying dalam Penjualan Online. Semarang : Skripsi Universitas Diponegoro

Luthans Fred (2014). Organizational Behavior. Ney York: McGraw-Hill. New York.

Mangkunegara, Prabu Anwar. (2016). Evaluasi Kinerja SDM. Cetakan ke tujuh, PT Refika Aditama: Bandung.

Rao, Purba, (2012). Measuring Consumer Perceptions Through Factor Analysis. The Asian.

Robbins, P.S, \& Judge, A.T. (2003). Organizational Behavior. Jakarta: Salemba Empat.

Santoso, Singgih (2015). Menguasai Statistik Multivariat. Jakarta: PT Elex Media Komputindo.

Sedarmayanti (2016) Manajemen Sumber Daya Manusia, Reformasi Birokrasi dan Manajemen Pegawai Negeri Sipil, Cetakan Kelima, Bandung: PT Refika Aditama.

Sudjana (2014). Metode Statistika. Bandung: Tarsido.

Sugiyono (2017). Metode Penelitian Administrasi dilengkapi dengan Metode R \& D. Bandung: Alfabeta.

Veithzal Rivai (2015) Manajemen Sumber Daya Manusia Untuk Perusahaan. Jakarta: Raja Grafindo Persada.

Wibowo (2015). Manajemen Kinerja. Jakarta: PT. Raja Grafindo Persada. 